\section{REVIEW OF SIPHONIC ROOF DRAINAGE SYSTEMS}

DAVID FUCIK, JAN RUCKA

Brno University of Technology, Faculty of Civil Engineering, Institute of Municipal Water Management, Brno, Czech Republic DOI : 10.17973/MMSJ.2019_12_2019156

e-mail : fucik.d@fce.vutbr.cz

The article describes an introduction to the problem of drainage of flat roofs, namely by using a vacuum drainage system. The article describes the current state, which also describes the gravity drainage system, whose design is in partial "retreat", unless required by local conditions or the investor of the construction. The following describes the advantages and disadvantages of the vacuum system and some design principles. The fourth chapter deals with the most common problems of the system, which include hydraulic system alignment, where the correct design of the system is carried out by hydraulic calculation of the system branches, using special software. The vacuum system must be designed in the correct dimensions, with suitable outlets and in such a way that it is not adversely affected by eg obstacles on the roof. Other mentioned problems include the level of noise and vibration of the system, which arises especially at higher intensity of rainfall, which leads to fluctuations between gravity and vacuum mode of water flow in the pipeline. These problems will be solved in the following research activity. Laboratory testing of hydraulic quantities and other parameters will be performed on a test equipment. The measured results will be further evaluated.

KEYWORDS

siphonic drainage system, roof drain, emergency drain, outlet, head of water, surface water

\section{INTRODUCTION}

Over the past 30 years, there has been a steady increase in the number of industrial and commercial roofs that are drained by a siphonic system. This increase is, to a large extent, influenced by the many advantages these systems have compared to gravity systems.

However, despite the increasing use of these systems, there are still uncertainties about how these systems work. This lack of understanding of the functioning of the system means that if the system fails, it is often difficult to evaluate why the problem occurred. Since the design of siphonic systems represents a higher level of expertise than required for gravity systems, the performance of these systems may be more prone to small inaccuracies and misconceptions. An increasing number of independent researches have been attempting to solve problems since 1995, trying to understand how siphonic systems actually work. [Arthur 2001]

The aim of this text is to introduce the reader to the basic problems of siphonic systems.

\section{EXISTING CONDITION}

The gravity drainage system of roofs is generally composed of gullies which are connected to down pipes. This is further connected to a horizontal pipe which is installed at an inclination to ensure drainage and self-cleaning effect. The diameter of the gullies is determined from the amount of rainfall in the area and from the surface of the drainage roof - the dimension is usually $100 \mathrm{~mm}$. [Arthur 2001]

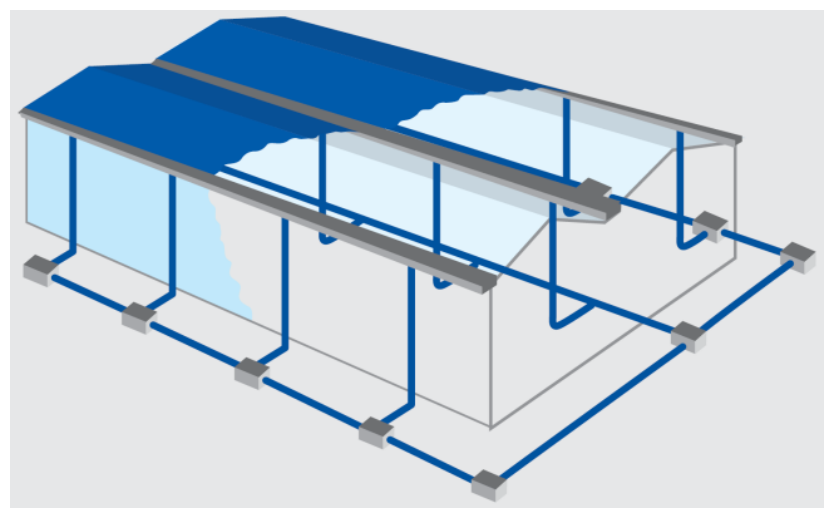

Figure 1. Gravity Roof Drainage System [Terrain 2019]

Compared to a gravity system, a siphonic system with equivalent drainage area can have a considerably higher capacity, as it is possible to achieve a flow across the entire cross-section of the pipe when rainwater flows. The siphonic system operates at pressures lower than atmospheric pressure, which is achieved when the flow rate across the pipe cross section is reached. [Arthur 2001]

The siphonic system is mostly used to drain flat roofs on nonresidential buildings such as production halls or shopping centers. The manifold is usually installed without a slope and is located under the roof structure. [Wavin 2015] Due to the smaller pipe dimensions, no large penetrations of roof structures, trusses or ceilings in the building are necessary. By limiting the drain lines that are typical of the gravity system, the functional space in the building is increased.

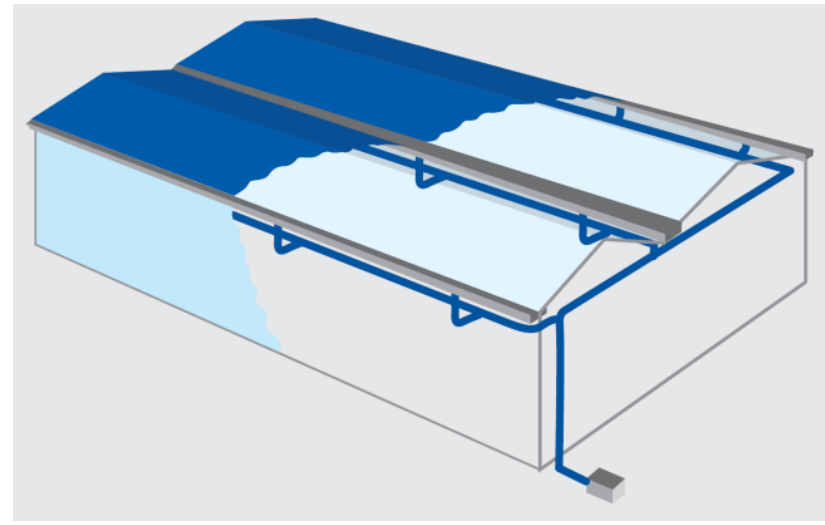

Figure 2. Siphonic Roof Drainage System [Terrain 2019]

The following figure (e.g. see Fig. 3) shows the flow of water in both the gravity and the siphonic systems. The gravity system is always constructed as partially filled. The water filling ratio is about $30 \%$ for down pipes [Hydromax] and about $70 \%$ for horizontal pipes. The rest of the pipe is filled with air. [Jagerska 2017]

In the downpipe the water flows down the walls of the pipe in the shape of a ring, the center of the pipe fills the air (the air core). [Hydromax]

The principle of operating the siphonic system is that the drain pipe is completely filled with rainwater, creating a siphonic 
effect at the roof drains and in the horizontal pipes. Full drainage of the drainage pipe is achieved by special roof drains, suitable sizing and hydraulic balancing. [Solar]

The installed piping must be gas-tight to prevent the air from entering the pipeline, causing the siphonic effect to fail. Welded HDPE pipes are most commonly used. [Zabicka 2007]

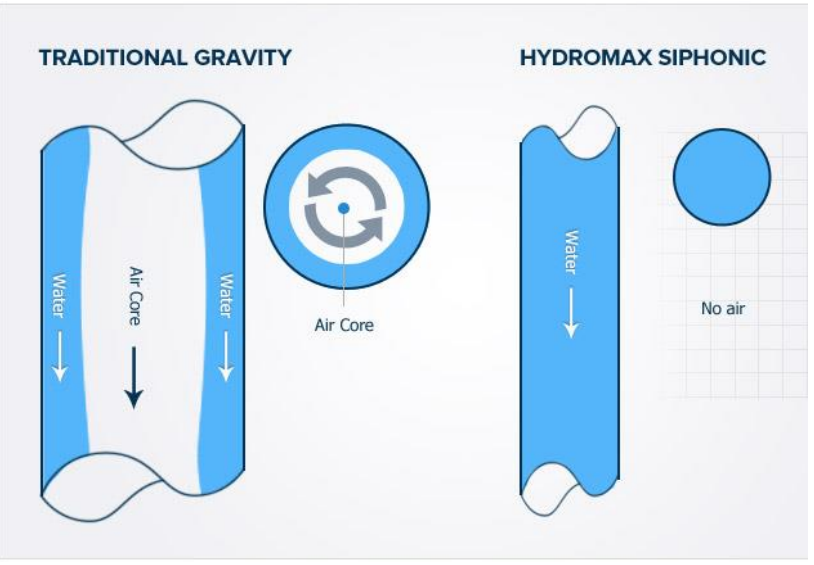

Figure 3. Water flow in the drain pipe [Hydromax]

If the rainfall intensity is exceeded, the building may be flooded, therefore it is necessary to design emergency drains through which the drain is directed to places where the resulting damage is limited. On the other hand, it is favorable to think about the maximum possible rainwater retention on the roof surface (so-called rainwater retardation), in order to hydraulically relieve the public sewer and also reduce the necessary dimensions of the entire system. In this case, the rainwater on the roof would be delayed for longer with the lower drainage capacity of the drains being drained.

\subsection{Advantages of siphonic systems}

In the case of a typical installation of a siphonic drainage system, the following advantages are obtained: [Solar; Kral 2017]

- High hydraulic capacity,

- Smaller pipe dimensions,

- Less down pipes, up to $80 \%$,

- The number of drains is reduced by about half, reducing the number of roof deck penetrations, thereby reducing the risk of possible roof leaks

- High water flow rates result in a self-cleaning effect,

- Reduction of earthworks,

- Shorter installation time,

- Furthermore, it is also possible to make it easier to connect to a public sewer, which is located at a lower depth where, in the gravity system, we would have to pump from a greater depth at the end of the horizontal pipe. We could get under the level of public sewerage because of the necessary slope of the horizontal pipe in the gravity system

These features in many cases allow significant time and money savings in the construction of both industrial and commercial buildings. As a result of elimination of down pipes, greater flexibility in the use of building space is achieved.

\subsection{Disadvantages of siphonic systems}

The main drawbacks of siphonic roof drainage systems include:

- The risk of overflow or static failure of the building structure, depending on the surcharge from the water,
- High noise level,

- Vibrations of drains and pipes created by water flow in the system

\subsection{Stages of pipe filling process}

As a result of rainfall, rainwater accumulates on the roof while rainwater is drained off through a roof drainage system pipe. At a higher or increasing rainfall rate, there is a higher filling of the drain pipes, which leads to the full bore flow of the pipeline. In general, this flow is divided into four stages of the pipe filling process.

\section{Gravity flow}

In the first phase of drainage emerging on the roof of a slight water, ie. up to $15 \%$ of the design intensity value add. The roof gullies function as a gravity system and the flow contains a large proportion of air. [Kral 2017]

AIR ABOVE WATER: GRAVITY FLOW

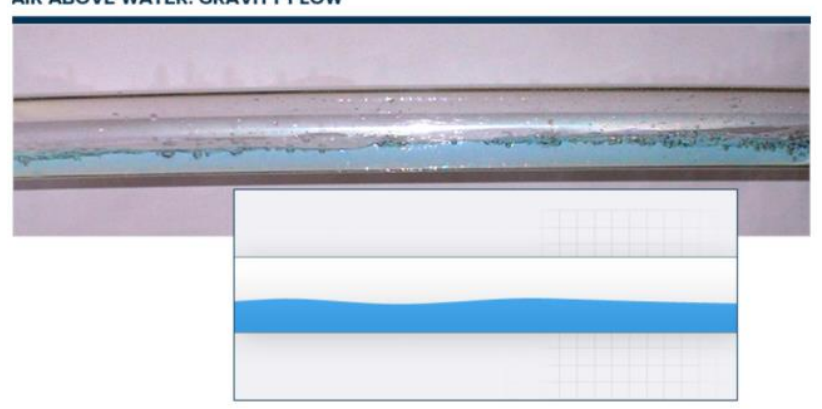

Figure 4. Gravity flow [Hydromax]

\section{Plug flow}

The second phase occurs when the degree of water filling from the roof is between $15 \%$ and $60 \%$ of the design value of the rainfall intensity. The water flow is discontinuous and the system therefore fluctuates between gravity and siphonic effect. At these rainfall values, the water on the roof will overwhelm the roof drain, avoiding the suction of air into the pipeline, thus triggering the siphonic mode. The water velocity in the pipeline therefore increases, resulting in a drop in the water level on the roof. This recovers air into the piping system, which disrupts the siphonic mode and returns to the gravity mode. [Kral 2017] There is a pulsation of the flow that takes place by periodically filling the pipeline in short lengths ("piston"). The plunger then displaces the air pockets that are trapped between the solid profiles. [Hydromax]

PLUG FLOW

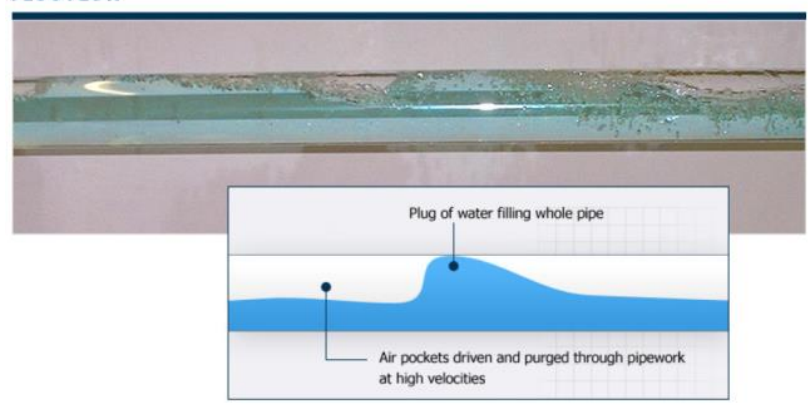

Figure 5. Plug flow [Hydromax]

3. Bubble flow

When the degree of water drainage from the roof is between $60 \%$ and $95 \%$ of the design value of the precipitation intensity, the pipeline is completely filled with water, although a large amount of air bubbles are 
still present in the pipeline. This stage is called bubble flow and is characterized by a high flow rate of water due to the created siphonic effect. [Kral 2017]

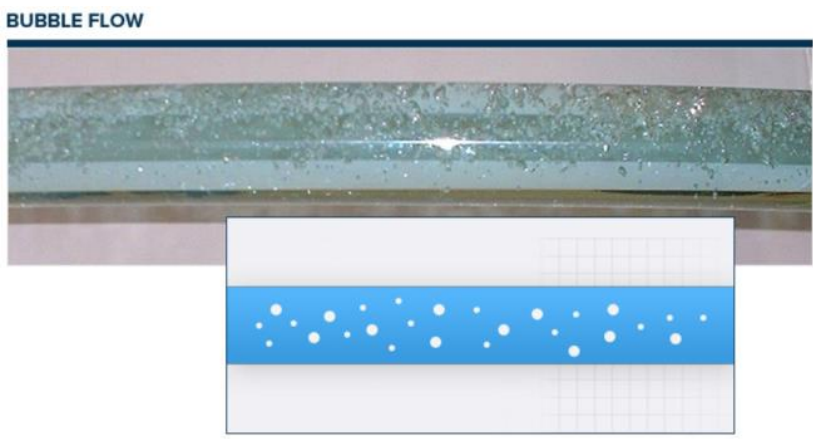

Figure 6. Bubble flow [Hydromax]

\section{Full bore}

When the degree of water drainage from the roof is greater than $95 \%$ of the design value of the precipitation intensity, the siphonic mode has the maximum effect and reaches the maximum water flow rate in the pipeline without any air suction. This stage is called full bore flow and essentially no noise or vibration is created in this mode. [Kral 2017] Preventing air access allows the system to operate at $100 \%$ water filling, making use of the entire pipe diameter and significantly increasing flow.

WATER FILLS THE WHOLE PIPE: FULL BORE

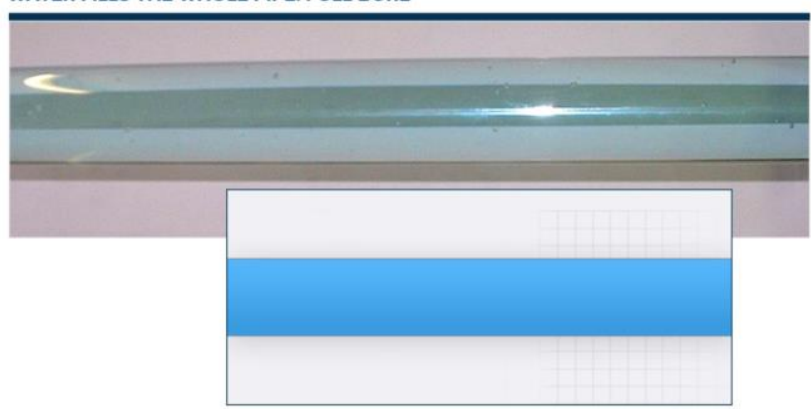

Figure 7. Full bore flow [Hydromax]

\section{DESIGN OF SIPHONIC SYSTEMS}

To create a vacuum effect in the pipeline, energy is needed due to the height difference between the roof inlet and the transition point of the vacuum and gravity system (downpipe where the inspection piece is fitted) or where the water flows into the open tank with free surface.

The design of the vacuum drainage system is carried out by its supplier, using special software on the basis of documents obtained from the designer. The software performs a hydraulic calculation of the entire system, resulting in a correct system design. The designer is responsible for the correct functioning of the vacuum system, hydraulic calculation, the layout of the outlets on the roof and also for the design of the dimensions of the individual sections of the pipeline. The output for the designer is the isometry of the individual branches of the pipeline, the bill of quantities with price to the project and the technical report. The vacuum system supplier should, if necessary, train the installer, provide on-site technical support or perform final checks of the entire system. [Janich 2012]

\subsection{Design principles}

Some of the following are some of the basic design principles: [Keidel 2012]

- Roof areas over $5.000 \mathrm{~m}^{2}$ must be drained by independent drainage down pipes,

- When draining roofs of different levels, it is recommended to drain each of the levels with a separate pipe branch,

- There may not be any obstacles in the route that would result in siphonic depletion,

- The down pipes dimension should not be increased for the drain pipe, as the siphonic effect in the pipeline would disappear,

- A cleaning piece is fitted at the interface of the siphonic and gravity systém,

- $\quad$ For the self-cleaning effect of the piping, a minimum water flow rate of $\min =0.7 \mathrm{~m} \cdot \mathrm{s}^{-1}$ is required,

- Maximum drain spacing is $20 \mathrm{~m}$,

- In hydraulic calculations, the siphonic value must not be less than $p=-0.09 \mathrm{MPa}$

Recommended principles for designing the shape and drainage of roofs according to CSN 73 1901. For example: [Solar]

- At least two roof drains should be designed for one roof area that is drained inside the buildings.

- Rain drain pipes from roofs that are led through unheated spaces should be tempered or designed to prevent freezing.

- No obstacles should hinder smooth drainage of water to the gutters or gates.

- Water drainage from roof surfaces through attic structures to outdoor rainwater drainage pipes should not be designed.

- Zaatik and inter-gutters should not be designed, especially in mountainous and mountainous areas.

- Roofs with internal drainage should be protected against freezing.

- Roofs with external drainage located above the heated areas should be designed to prevent the formation of ice walls at the edge of the roof and the risk of subsequent water leakage to the roof.

- If the waterproofing coatings are led to the upper surface of the attic, they are usually protected by sheet metal. The sheet metal must have a slope of at least $3^{\circ}$ to the roof surface.

- It is recommended that the drains be thermally insulated, heated or provided with thermal insulation covers.

- If the drain fitting is tempered by contact of the drain pipe with the internal environment, it is necessary to ensure a controlled drainage of any condensate from the pipe surface.

- Waste ducts through ventilated air layers of multiskin roofs are thermally insulated.

- Drains and pipe penetrations should not be placed in leeward corners of roofs, in the immediate vicinity of attics or other roof structures (roof extensions, chimneys, etc.). The distance of these places should be at least $0.5 \mathrm{~m}$, preferably $1 \mathrm{~m}$.

\subsection{Emergency overflow}

Failure to drain captured rainwater on the roof could cause a serious problem, which would be a roof overflow. In the worst case, the roof structure could be damaged or collapsed due to an accidental load due to water backflow (the weight 
of water per $1 \mathrm{~m} 2$ at a height of $10 \mathrm{~cm}$ is approximately $100 \mathrm{~kg}$ ). This could occur in case of higher intensity of rainfall than their design value. In this case, the roof filling would be faster than the drainage capacity of the designed outlets. Consequently, it is necessary to carry out a static roof check to determine the maximum permissible level on the roof.

To avoid these problems, an emergency overflow must be able to ensure the trouble-free drainage of the 100-year rainfall expected at the building site for five minutes. The capacity of emergency spillways results from the difference between a hundred-year rainfall and the maximum drainage capacity of a vacuum roof drainage system. [VDI 2010] The emergency overflow pipeline cannot be connected to the primary drainage system and must be routed outside the building.

The basic types of emergency weirs installed on buildings include the following variants (eg see Fig. 8): [Keidel 2012]

- A - Emergency overflow as openings in the attic, which may be circular or rectangular,

- B - Emergency drains installed in the attic,

- C - Emergency drains installed in the roof area
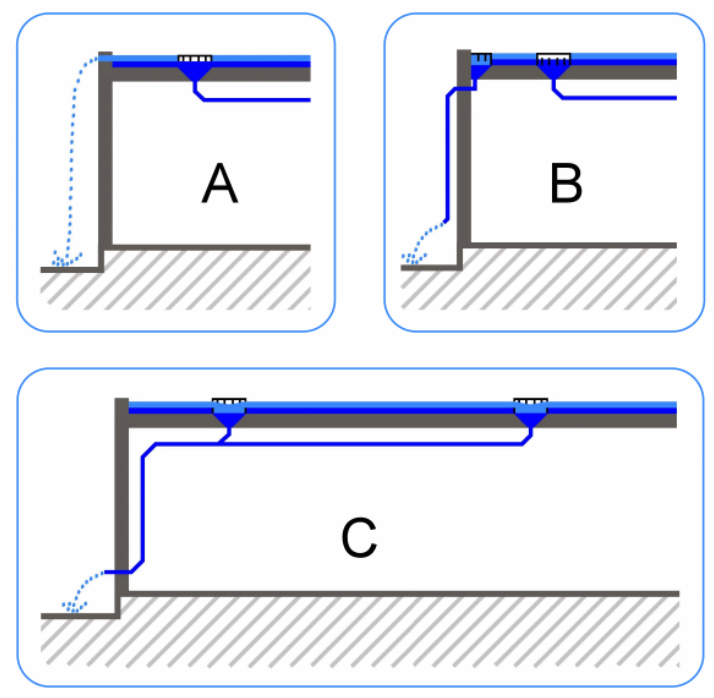

Figure 8. Emergency overflows [Keidel 2012]

\section{PROBLEMS OF SIPHONIC ROOF DRAINAGE SYSTEMS}

It is generally known there are some problems with the roof drainage systems. However, it is assumed that the number of failures is only a small percentage of installed systems worldwide. There is no evidence to suggest that vacuum systems are more prone to failure than gravity drainage systems. [Campbell]

If there were system failures, they were due to one or more of the following: [Campbell]

- Insufficient understanding of operating characteristics,

- Material defects,

- Installation defects,

- Poor maintenance

The roof drain material must be resistant to rainwater, UV radiation, local climatic conditions and, if necessary, hot bitumen. The floor drain material must be resistant to a maximum occasional waste water temperature of $95^{\circ} \mathrm{C}$. They must also withstand the expected stresses during installation and operation. [CSN EN 1253-2] The installation of the system should be carried out by a qualified person, thus reducing the risk of these installation defects. The system maintenance is related to the outlets and system checks, which should be carried out at least twice a year, according to the standard CSN 756760.

\subsection{Balancing Siphonic Drainage Systems}

A persistent problem is the design of the system and its balancing in terms of hydraulic alignment in the pipeline, especially at the joints of individual branches.

The purpose of balancing the vacuum manifold system is to ensure efficient use of driving height from the height of the building. This is done by balancing the total loss of the pipe system with the effective height. When designing vacuum systems, the goal is to balance the difference between the maximum and minimum calculated residual height in each part of the system. The ideal vacuum system will have a total calculated energy loss through the duct system equal to the available design height. [D.P.L.G. 2010]

In practice, however, it is usually not possible to balance residual heights accurately. Therefore, there will be some imbalance. It is recommended that the maximum unbalance value in the vacuum system be up to $0.5 \mathrm{~m}$ or $10 \%$ of the design height. [D.P.L.G. 2010]

Reasons why exact height balance is not possible: [D.P.L.G. 2010]

- Pipe is only available in certain dimensions,

- The designer does not have complete freedom when placing pipes and fittings,

- Loss coefficients are not accurate and may vary with different flow conditions, such as speed and amount of air present in the stream

Thus, vacuum systems require careful selection of pipe sizes as opposed to conventional gravity systems. In vacuum systems, typically, each end pipe configuration is different. This is because the design solver uses either a different pipe diameter or a different armature to achieve the required losses to balance the system. [D.P.L.G. 2010]

Unbalanced systems are likely to experience functional problems, including: [D.P.L.G. 2010]

- The roof drainage system could have a lower rainwater drainage capacity than indicated,

- The drain function may be irregular,

- Rain water from high-level roofs can flow to lower roofs,

- Outlets near the downpipes could suck in the air and thus "interrupt" the vacuum effect

These problems can lead to considerably reduced drainage performance, acoustic problems and dynamic loading of the installed pipeline. [D.P.L.G. 2010]

The basic goal of a balanced vacuum system is to achieve equal flow rates in the every drains. The same flow rates are achieved by balancing the friction and creating losses in the pipe system. [D.P.L.G. 2010]

This can be achieved by changing: [D.P.L.G. 2010]

- Pipe diameter,

- Drain type,

- Pipe length,

- Use of reducers 
The objective of the proposal will vary depending on the location of implementation, but in most cases the key objective will be to prevent flooding of the building and surrounding surfaces, eventually the accumulation and re-use of rainwater. A well designed vacuum system achieves flood protection objectives. [D.P.L.G. 2010]

Another problem related to hydraulics in the system piping could arise when draining roofs of different levels, where at a higher difference, water could flow to a lower roof through a lower drain.

For this reason, it is recommended that each level be drained through its own duct, except where the roof height difference is less than or equal to $1 \mathrm{~m}$ (eg see Fig. 9). The other two prohibitions in the figure indicate an area with an obstruction that would cause the vacuum effect to disappear, and a space with a minimum height of the downpipe that is required to create a vacuum effect in the system. [Keidel 2012]

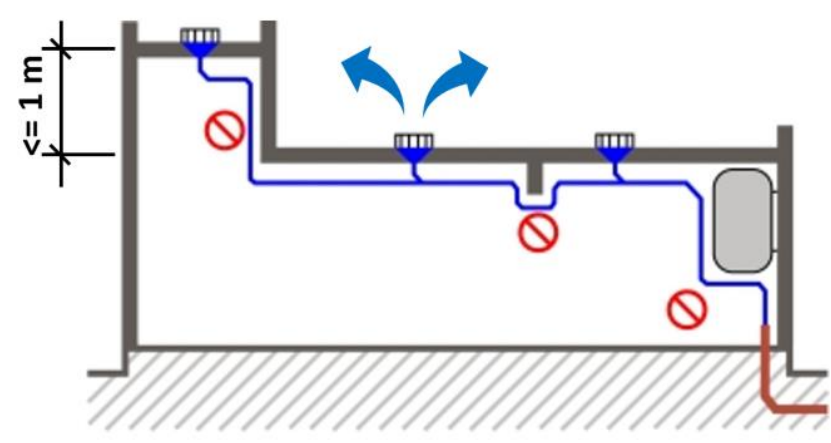

Figure 9. Problems leading to the disappearance of the siphonic effect [Keidel 2012]

\subsection{Flow and noise levels}

It should be noted that when the rainwater flows into the drain and then the water flows in the siphonic system pipe sections, there is a strong noise that is accompanied by vibrations, both drain drains and pipe sections. In particular, a very strong noise is generated when the rainwater drainage is partially filled, when the pipe profile is filled with both water and air. When using a transparent wall pipe, the visually partial filling of the storm sewerage system appears opaque (e.g. see Fig. 10). Full filling of the storm sewer, when the pipe profile is filled only with water, results in a low noise level. Optically, full drainage of the rainwater drainage system is transparent (e.g. see Fig. 10); the 4th phase of the pipe filling process - Full bore flow. [Preserved 2018]
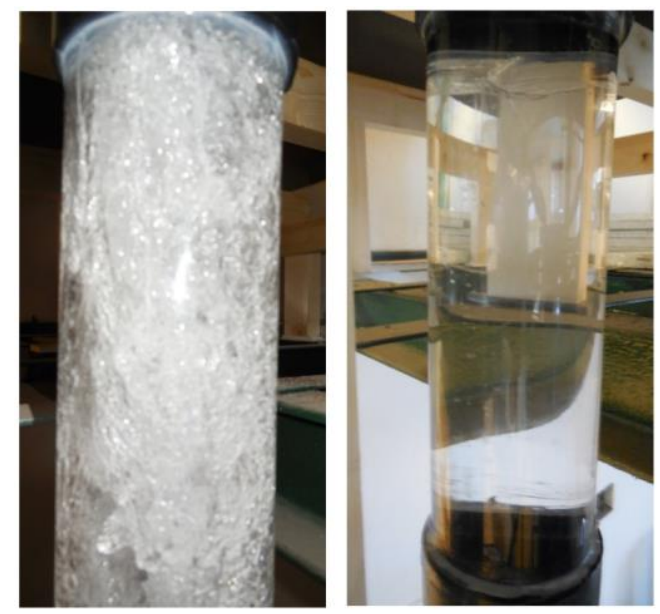

Figure 8. Example of pipe flow transparency [Zachoval 2018]
Strong noise is caused by entrainment of air towards the pipe part of the siphonic system. Most siphonic drains are specifically designed to reduce the amount of air entering the system. This is often achieved with a horizontal baffle (Air Baffle), which is part of the siphonic drain and is located at the drain to the pipe. Air Baffle restricts vortex formation over the drain that would suck air into the system and break the siphonic mode. The location of the air baffle is shown in the figure (e.g. see Fig. 11) where a simple scheme of the siphonic system is shown. Another option may be to place the so-called "inverted dish" on the drain, which constitutes the air chamber, thereby limiting the entrainment of air into the duct. [Lucke 2007]

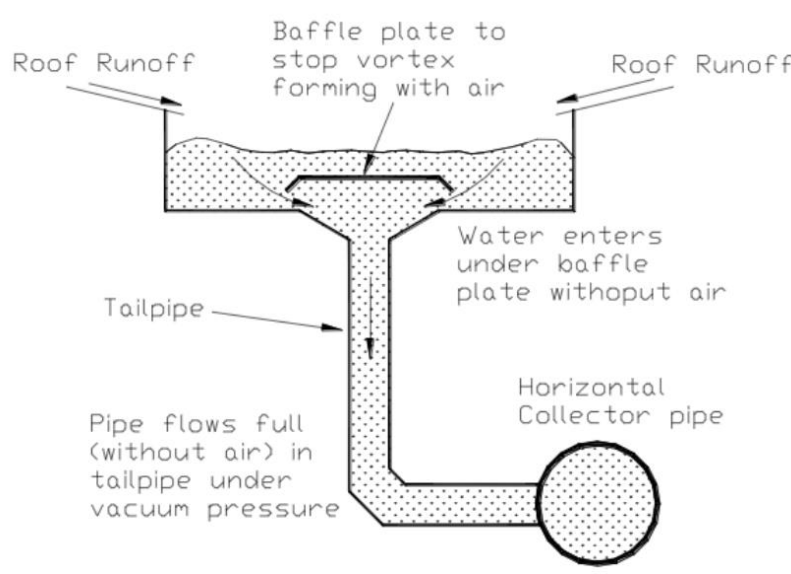

Figure 9. Siphonic system with air baffle at the drain [Lucke 2007]

As far as the aforementioned vibrations are concerned, they occur when the rainwater enters the drain part of the roof drainage system, are captured and damped by the anchoring elements (e.g. see Fig. 12).

Anchorage systems include a variety of components such as pipe clamps, guide collectors that are anchored to ceilings and many more. The anchoring elements are generally anchored to the supporting structures into which the unfavorable static and dynamic stresses are transmitted. [VDI 2010]

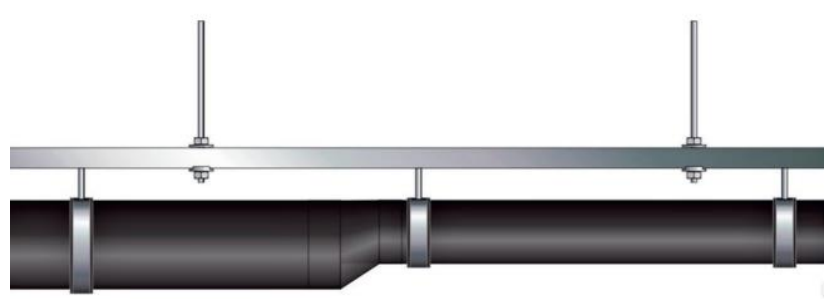

Figure 10. An example of pipe anchorage with eccentric diameter reduction [Schilhart 2017]

\section{CONCLUSIONS}

The article acquaints the reader with the basic issue of roof drainage using vacuum systems. Also described are the most common problems that must be faced by everybody who proposes a given system with the fact that the level of problems depends on the locality of the project.

Two basic systems are used for drainage of flat roofs, which include gravity drainage and vacuum drainage, which has its advantages, but its design is much more complicated, so it must be carried out by an experienced person. In both cases, however, it is necessary to carry out pre-project preparation, 
the details and accuracy of which may significantly affect the function of the entire roof drainage system. The article describes basic information about the vacuum system of roof drainage with an emphasis on the emergence of potential problems of the system and their possible prevention or eventually their elimination. Of course, the desirable condition is that these adverse effects do not arise at all, so that the system operates with maximum efficiency.

In the following research activity a complete construction with elements of a vacuum system of flat roof drainage will be designed. Furthermore, a system model will be developed, according to which a test facility will be built for laboratory testing of hydraulic quantities for different inlet and piping dimensions and for different system piping routes. Other secondary measured parameters will be the noise level of the water flow in the system and the amount of vibrations generated. The measured data will be compared for different system elements and different system assemblies. Subsequently, the evaluation of the comparison will be performed.

\section{ACKNOWLEDGMENTS}

The work was financed from the budget of the project "Selected Problems of Public Drinking Water Supply Systems", registration number FAST-S-18-5526, which is financed from the Program of Specific Higher Education Research at the Brno University of Technology.

\section{REFERENCES}

\section{Book:}

[Zabicka 2007] Zabicka, Z., et al. Building drainage - 2nd supplemented edition. Era publisher, 2007. ISBN: 80-7366-077-6 (In Czech)

\section{Paper in proceedings:}

[Campbell] Campbell, D. P., Innovations in Modulated Flow and Self Configuring Siphonic Roof Drainage Systems. Drainage Research Group. School of the Built Environment, Heriot Watt University, Edinburgh, Scotland U.K.

[Lucke 2007] Lucke, T., et al. Rainwater harvesting options for commercial buildings using siphonic roof drainage systems----Lessons for Building Surveyors. International Transitions Conference, Australian Industry of Building Surveyors, Adelaide, 2007. University of South Australia, School of Natural and Built Environments, 1-11.

\section{Technical reports or thesis:}

[CSN EN 1253-2] Czech technical standard. Gullies for buildings - Part 2: Roof drains and floor gullies without trap. ICS 91.140.80. Czech Office for Standards, Metrology and Testing, 2016.

[D.P.L.G. 2010] Department of Planning and Local Government. Siphonic Roofwater Systems. Water Sensitive Urban Design Technical Manual for the Greater Adelaide Region. Government of South Australia, 2010. ISBN: 978-1-876702-99-1
[Jagerska 2017] Jagerska, L. Analysis of roof drainage by siphonic sewer systems. Dissertation thesis. License number: SvF-13422-10536. Slovak University of Technology in Bratislava: Faculty of Civil Engineering, 2017. (In Slovak)

[Schilhart 2017] Schilhart, E. Design of Flat Roof Drainage 2, Siphonic Systems. Brno: TOPWET s.r.o., 2017. (In Czech)

[Terrain 2019] Terrain. Siphonic Roof Drainage. Aylesford: Polypipe Building Services, 2019.

[VDI 2010] VDI 3806. Siphonic roof drainage. ICS 91.140.80. German: Union of German Engineers, 2010. (In German)

[Zachoval 2018] Zachoval, Z. Determination of capacity of siphonic and gravity drains. Final Report. Brno University of Technology, Faculty of Civil Engineering, Institute of Water Structures, 2018. (In Czech)

Paper in electronic journal:

[Arthur 2001] Arthur, S., Swaffield, J. A. Siphonic roof drainage: current understanding [online]. March-June 2001, Vol: 3, Issue: 1, 2001 [05.06.2019]. Available from <https://www.sciencedirect.com/science/article/pii S1462075801000218?via\%3Dihub>. ISSN: 14620758

[Janich 2012] Janich, J. How does the Akasison siphonic drainage system work?. [online]. May 2012 [03.06.2019]. Available from <https://stavba.tzbinfo.cz/odvodnovaci-systemy/8555-jak-fungujesystem-podtlakoveho-odvodneni-plochych-strechakasison>. (In Czech)

\section{WWW page:}

[Hydromax] HydroMax. How does hydromax siphonic drainage work. [online]. [03.06.2019]. Available from $<$ http://www.hydromax.com/144 HowdoesHydro MaxSiphonicDrainageWork.html>.

[Jagerska 2018] Jagerska, L. Investment costs for gravity and siphonic systems. Publisher, 2018, [online]. 19.02.2018 [05.06.2019]. Available from $<$ https://www.asbportal.cz/stavebnictvi/strecha/investicni-nakladyna-gravitacni-a-podtlakovy-system>. (In Slovak)

[Keidel 2012] Keidel. Learning Siphonic Roof Drainage. [online]. 2012 [02.06.2019]. Available from $<$ http://www.learning-siphonic-roofdrainage.com/contents.html>.

[Kral 2017] Kral, J. TOPWET siphonic drainage systems. 2017, [online]. 23.03.2017 [02.06.2019] Available from $<$ https://www.strecharska-mapa.cz/strecharskamapa/podtlakove-odvodnovaci-systemy-topwet/>. (In Czech)

[Solar] Solar, J. Roof drainage. [online]. [03.06.2019]. Available from <http://fast10.vsb.cz/studijnimaterialy/ps4/2.html>. (In Czech)

[Wavin 2015] Wavin. Drainage of flat roofs: gravity or siphonic system?. [online]. 2015 [10.06.2019]. Available from $<$ https://www.wavinacademy.cz/wpcontent/uploads/2015/10/31 Materialy-prostavbu odvodneni-plochychstrech 150401 FIN.pdf>. (In Czech) 


\section{CONTACTS:}

Ing. David Fucik

Ing. Jan Rucka, Ph.D.

Brno University of Technology, Faculty of Civil Engineering,

Institute of Municipal Water Management,

Veveri 331/95 Street, 60200 Brno, Czech Republic

+420 774927 250, fucik.d@fce.vutbr.cz

+420 604794 350, jan.rucka@vut.cz

https://www.vutbr.cz/ 